\title{
Effect of Vasopressin on the Hypothalamic- Pituitary-Adrenal Axis in ADPKD Patients during V2 Receptor Antagonism
}

\author{
Judith E. Heida ${ }^{a} \quad$ Isidor Minovićb Martijn van Faassen ${ }^{b} \quad$ Ido P. Kema ${ }^{b}$ \\ Wendy E. Boertien ${ }^{\mathrm{a}}$ Stephan J.L. Bakker ${ }^{\mathrm{a}} \quad$ André P. van Beek ${ }^{\mathrm{c}}$ \\ Ron T. Gansevoort ${ }^{a}$ \\ aDepartment of Nephrology, University Medical Center Groningen, University of Groningen, Groningen, \\ The Netherlands; ${ }^{b}$ Department of Laboratory Medicine, University Medical Center Groningen, University of \\ Groningen, Groningen, The Netherlands; ' Department of Endocrinology, University Medical Center \\ Groningen, University of Groningen, Groningen, The Netherlands
}

\section{Keywords}

Autosomal dominant polycystic kidney disease $\cdot \mathrm{V} 2$ receptor antagonist · Cortisol · Glucocorticoid metabolites

\begin{abstract}
Background: Patients with autosomal dominant polycystic kidney disease (ADPKD) are treated with a vasopressin V2 receptor antagonist (V2RA) to slow disease progression. This drug increases vasopressin considerably in these patients with already elevated baseline levels. Vasopressin is known to stimulate the hypothalamic-pituitary-adrenal (HPA) axis through $\mathrm{V} 1$ and $\mathrm{V} 3$ receptor activation. It is unknown whether this increase in vasopressin during V2RA treatment affects glucocorticoid production. Methods: Twenty-seven ADPKD patients were studied on and off treatment with a V2RA and compared to age- and sex-matched healthy controls and IgA nephropathy patients, the latter also matched for kidney function. Vasopressin was measured by its surrogate copeptin. Twenty-four-hour urinary excretions of cortisol, cortisone, tetrahydrocortisone, tetrahydrocortisol, allotetrahydrocortisol, and the total glucocorticoid pool were measured. Results: At baseline, ADPKD patients demonstrated a higher copeptin concentration in comparison with healthy
\end{abstract}

karger@karger.com www.karger.com/ajn

Karger"

BOPEN ACCESS
(C) 2020 The Author(s)

Published by S. Karger AG, Basel

This is an Open Access article licensed under the Creative Commons Attribution-NonCommercial-4.0 International License (CC BY-NC) (http://www.karger.com/Services/OpenAccessLicense), applicable to the online version of the article only. Usage and distribution for commercial purposes requires written permission. controls, while urinary excretion of cortisol and cortisone was lower (medians of $0.23 \mathrm{vs} .0 .34 \mu \mathrm{mol} / 24 \mathrm{~h}, p=0.007$, and 0.29 vs. $0.53 \mu \mathrm{mol} / 24 \mathrm{~h}, p<0.001$, respectively). There were no differences in cortisol and cortisone excretion compared to IgA nephropathy patients. Cortisol, cortisone, and total glucocorticoid excretions correlated with kidney function $(R=0.37,0.58$, and 0.19 , respectively; all $p<0.05)$. Despite that V2RA treatment resulted in a 3-fold increase in copeptin, only cortisone excretion increased (median of $0.44 \mathrm{vs}$. baseline $0.29 \mu \mathrm{mol} / 24 \mathrm{~h}, p<0.001$ ), whereas no changes in cortisol or total glucocorticoid excretion were observed. Conclusions: Increased concentration of vasopressin in ADPKD patients at baseline and during V2RA treatment does not result in activation of the HPA axis. The impaired glucocorticoid production in these patients is related to their degree of kidney function impairment.

(c) 2020 The Author(s) Published by S. Karger AG, Basel

\section{Introduction}

Autosomal dominant polycystic kidney disease (AD$\mathrm{PKD}$ ) is a genetic disease characterized by growth of numerous cysts in the kidneys, causing kidney function to 
decline [1]. An increasing number of ADPKD patients are nowadays treated with tolvaptan, a vasopressin V2 receptor antagonist, to slow their rate of disease progression [2-5]. In the kidney, binding of vasopressin to V2 receptors initiates translocation of aquaporin channels to the cell membrane of collecting duct cells. These channels allow water to flow from the lumen of tubular cells into the interstitial tissue and adjacent capillaries, thus reducing urinary output [6]. By blocking this signal, a vasopressin V2 receptor antagonist causes an increase in urine volume and plasma osmolality, leading to a compensatory release of vasopressin from the neuropituitary gland. Tolvaptan is highly selective for the V2 receptor and does not block vasopressin action on the V1 and V3 receptors [7]. Elevated levels of vasopressin during tolvaptan use will therefore result in activation of these other two vasopressin receptor subtypes. Whether this will lead to clinically relevant secondary effects is not known.

One of these theoretical secondary effects could be activation of the hypothalamic-pituitary-adrenal (HPA) axis [8-11]. In experimental models, vasopressin has been demonstrated to potentiate the effect of corticotropin-releasing hormone $(\mathrm{CRH})$ via binding to V3 receptors on the adenohypophysis [12-14]. Vasopressin stimulation thus increases adrenocorticotropic hormone (ACTH) release. Additionally, vasopressin can also induce cortisol secretion directly via binding to both V1 and V3 receptors on the adrenal cortex $[15,16]$. Studying the HPA axis in ADPKD patients could generate new insights regarding the effect of vasopressin on cortisol production. An increase in glucocorticoids might be of clinical importance. It has been suggested that even a subtle elevation of cortisol can increase the incidence of cardiovascular events and mortality [17, 18]. Given that ADPKD patients are already known to have a high burden of cardiovascular problems, the possibility of adding to this risk is a cause for concern [19, 20].

In the present study, we investigated, therefore, first baseline HPA axis activity in ADPKD patients, by comparing them with healthy controls and IgA nephropathy patients with a similar level of kidney function impairment. The latter group was added to consider whether changes in urinary glucocorticoid excretion are an $\mathrm{AD}$ PKD specific phenomenon or can be attributed to lower kidney function in general. Thereafter, the effect of the increase in vasopressin levels during V2 receptor antagonist treatment on glucocorticoid metabolism was studied.

\section{Materials and Methods}

\section{Study Population}

For the present investigation, we used data of a study that was conducted between 2011 and 2013 to investigate the hemodynamic effects, safety, and pharmacokinetics of short-term use of the V2 receptor antagonist tolvaptan in 27 ADPKD patients with a wide range in kidney function. The design and main findings of this study have been reported previously [3]. In summary, the Ravine criteria were used to diagnose ADPKD [21]. Main exclusion criteria were a BMI of $>35 \mathrm{~kg} / \mathrm{m}^{2}$, uncontrolled hypertension, diabetes mellitus, pregnancy or breastfeeding, critical electrolyte imbalances, use of diuretics, and the need for kidney replacement therapy. Patients were on stable antihypertensive therapy during the study. Plasma and 24-h urine samples were collected at baseline, and after 3 weeks use of a V2 receptor antagonist (given as 90 $\mathrm{mg}$ at 8:00 and as $30 \mathrm{mg}$ at 17:00), and 3 weeks after stopping this medication.

Every ADPKD patient was matched to 3 healthy controls based on age and sex. The healthy controls were chosen at random from an observational cohort of kidney transplant donors from our center [22]. Subjects are eligible for organ donation if they are in good health, in particular, without impaired kidney function or increased albuminuria. Urine and plasma samples collected before kidney donation were used.

A second control group was created to investigate the influence of kidney function by matching ADPKD patients with IgA nephropathy patients 1:1 for age, sex, and estimated glomerular filtration rate (eGFR). Patients with IgA nephropathy were chosen as control group because we aimed at a uniform group and $\operatorname{IgA}$ nephropathy is the most common primary kidney disease. These IgA nephropathy patients were selected from our outpatient clinic.

These studies were approved by the ethical board of the University Medical Center Groningen and conducted in adherence to the International Conference on Harmonization - Good Clinical Practice. Written informed consent was obtained.

\section{Laboratory Measurements}

Because of the variability in plasma levels over the day, measurement of daily cortisol production is best represented by the total amount of glucocorticoids in a 24-h urine sample. This includes not only cortisol but also its metabolites. Therefore, the urinary excretion of cortisol, its counterpart cortisone, and the majority $(\sim 80 \%)$ of their breakdown products tetrahydrocortisone (THE), tetrahydrocortisol (THF), and allotetrahydrocortisol (aTHF) were measured [23]. The total active pool was defined as the sum of cortisol and cortisone urinary excretion. The balance between cortisol and cortisone is maintained by 2 types of $11 \beta$-hydroxysteroid dehydrogenase (11 $\beta$-HSD), types 1 and 2 , of which the activities can be estimated by calculation of the (THF + aTHF)/THE and cortisone/cortisol ratios, respectively [24, 25]. Furthermore, the activity of the $5 a$-reductase enzyme can be calculated using the urinary aTHF/THF ratio $[26,27]$.

Total urinary cortisol, cortisone, THF, aTHF, and THE were measured using a validated high-performance liquid chromatography tandem mass spectrometry assay [27]. For all components, stable isotope labelled internal standards were added, and the mixtures were incubated with an enzyme solution consisting of sulfatases and $\beta$-glucuronidases (Suc d'Helix Pomatia; Brunschwig Chemie, Amsterdam, The Netherlands), to ensure hydrolysis of 
Table 1. Baseline characteristics of ADPKD patients, matched HCs, and matched IgA nephropathy patients

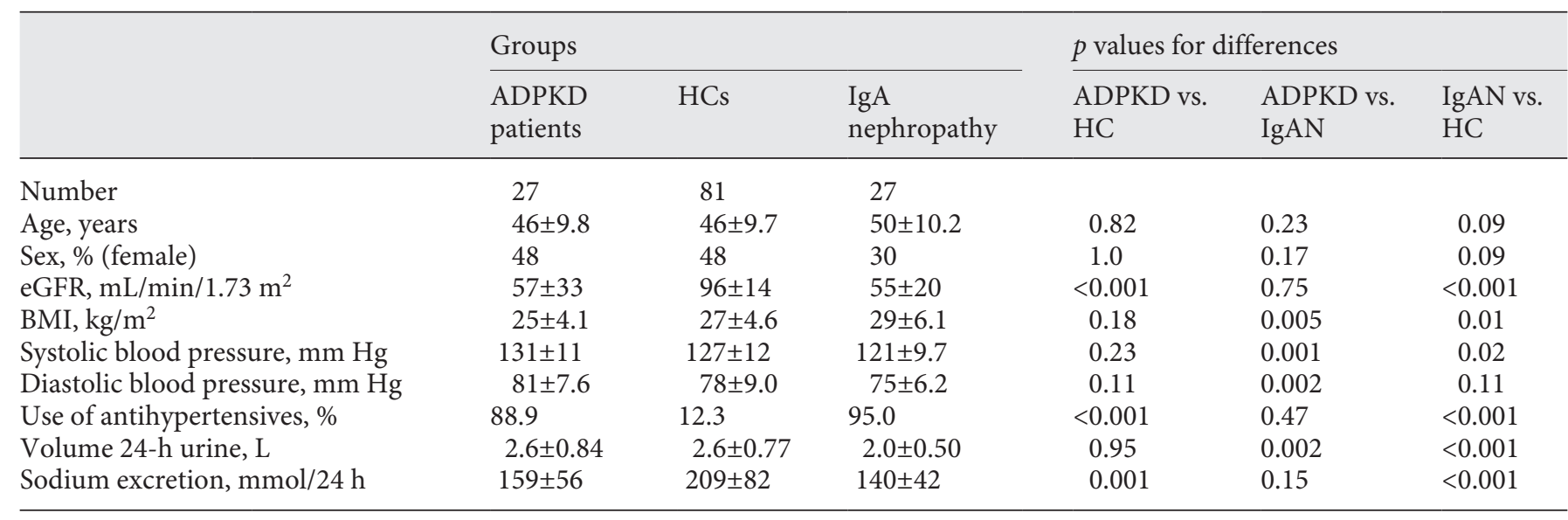

Data presented as mean $\pm \mathrm{SD}$, differences tested with an independent sample $t$ test. eGFR, estimated glomerular filtration rate; ADPKD, autosomal dominant polycystic kidney disease; Ig, immunoglobulin; HC, healthy control; SD, standard deviation.

cortisol and the metabolites from their sulfated and glucuronidated forms. Subsequently, analytes were extracted using a Supported Liquid Extraction technique (Phenomenex, Torrance, CA, USA). Finally, separation and detection were performed by use of a CSH Phenyl-Hexyl column (particle size $1.7 \mu \mathrm{m}, 2.1 \times 100 \mathrm{~mm}$; Waters, Milford, MA, USA) and a XEVO TQ- ${ }^{\circledR}$ tandem mass spectrometer operated in negative electrospray ionization mode (Waters, Milford, MA, USA), respectively. Inter-assays imprecision was $\leq 5.1, \leq 9.2, \leq 2.5, \leq 6.5$, and $\leq 8.0 \%$ for cortisol, cortisone, THE, THF, and aTHF, respectively.

In addition, we included plasma cortisol, cortisone, corticosterone, 11-deoxycortisol, and 11-deoxycorticosterone levels in our analysis as secondary outcome measures. Blood was drawn at clinic visits between 8:00 and 12:00 a.m. For plasma measurement, we used an online SPE LC-MS/MS assays, with use of a Kinetex Biphenyl column (particle size $2.6 \mu \mathrm{m}, 2.1 \times 100 \mathrm{~mm}$; Phenomenex, Torrance, CA, USA). Mass spectrometric detection was performed in positive electrospray ionization mode with a XEVO TQ-s (Waters, Milford, MA, USA). Inter-assay imprecision was $\leq 4.0, \leq 6.0$, $\leq 4.0, \leq 3.8$, and $\leq 8.1 \%$ for cortisol, cortisone, corticosterone, 11 -deoxycortisol, and 11-deoxycorticosterone, respectively. The combined $11 \beta$-HSD type 1 and type 2 activity was estimated with the ratio between cortisol and cortisone plasma levels. The CYP11B1 and CYP11B2 activities were estimated with the ratios between cortisol and 11-deoxycortisol and between corticosterone and 11-deoxycorticosterone, respectively [28].

All urine and plasma samples were stored at $-80^{\circ} \mathrm{C}$ until laboratory analysis. Cold storage times were nearly similar for our study groups; therefore, little bias is expected from freeze-thaw effects. In particular, considering that various studies have shown that prolonged frozen storage does not affect cortisol levels [2931].

Copeptin was measured as surrogate marker for vasopressin, on a semi-automatic Kryptor analyzer (Thermo Fisher, Henningsdorf/Berlin, Germany) using a sandwich chemiluminescence immunoassay (Thermo Fisher) [32]. The intra-assay coefficient of variation of copeptin was $9.0 \%$ in the low range (at $3.0 \pm 0.3$ $\mathrm{pmol} / \mathrm{L}$ ) and $2.2 \%$ in the high range (at $28.9 \pm 0.6 \mathrm{pmol} / \mathrm{L}$ ). The inter-assay coefficient of variation of copeptin was 13.1 and $2.2 \%$ for the low and high range, respectively [32]. Measurement methods for other laboratory variables have been described previously [3].

\section{Statistical Analysis}

Variables with a normal distribution are presented as mean and standard deviation, whereas variables with a skewed distribution are presented as median and interquartile range (IQR). Parametric data were assessed with use of the paired samples $t$ test. Nonparametric data were compared with use of either the Mann-Whitney U test or Friedman's ANOVA with a post hoc analysis of differences using Wilcoxon signed-rank tests, with Bonferroni corrections to correct for multiple testing. Correlations between eGFR and glucocorticoids were assessed using Spearman's correlation analysis and, after log transformation, with multivariate regression analysis. $p$ values of $<0.05$ were considered statistically significant. Analyses were performed using SPSS (IBM Statistics version 22.0) and GraphPad Prism (version 5.0).

\section{Results}

\section{Baseline Characteristics}

In Table 1, the baseline characteristics of 27 ADPKD patients are compared to those of 81 age- and sex-matched healthy controls and age-, sex-, and kidney functionmatched 27 IgA nephropathy patients. As expected, both groups of patients had lower kidney function than healthy control group. Furthermore, 24-h urinary sodium excretion was lower in ADPKD and IgA nephropathy patients, reflecting adherence of these patients to the advice to restrict their sodium intake. 
Table 2. Urinary excretion of glucocorticoids in ADPKD patients compared to matched HCs and IgA nephropathy patients

\begin{tabular}{|c|c|c|c|c|c|c|}
\hline & $\begin{array}{l}\text { ADPKD } \\
\text { patients }\end{array}$ & $\mathrm{HCs}$ & IgA nephropathy & $\begin{array}{l}\text { ADPKD vs. } \\
\text { HC }\end{array}$ & $\begin{array}{l}\text { ADPKD vs. } \\
\text { IgAN }\end{array}$ & $\begin{array}{l}\text { IgAN vs. } \\
\mathrm{HC}\end{array}$ \\
\hline Total glucocorticoids, $\mu \mathrm{mol} / 24 \mathrm{~h}$ & $21.7[14.2-28.4]$ & $22.2[13.3-39.6]$ & $22.7[16.9-31.6]$ & 0.32 & 0.31 & 0.96 \\
\hline \multicolumn{7}{|l|}{ Active compounds } \\
\hline Total active pool, $\mu \mathrm{mol} / 24 \mathrm{~h}$ & $0.51[0.42-0.73]$ & $0.88[0.95-1.21]$ & $0.57[0.48-0.79]$ & $<0.001$ & 0.26 & $<0.001$ \\
\hline \multicolumn{7}{|l|}{ Metabolites } \\
\hline $\mathrm{THE}, \mu \mathrm{mol} / 24 \mathrm{~h}$ & $9.27[6.14-14.6]$ & $10.7[6.54-19.9]$ & $10.2[7.42-15.0]$ & 0.13 & 0.40 & 0.45 \\
\hline $\mathrm{THF}, \mu \mathrm{mol} / 24 \mathrm{~h}$ & $5.91[4.07-7.88]$ & $6.13[3.91-10.2]$ & $5.81[4.07-8.91]$ & 0.50 & 0.90 & 0.75 \\
\hline $\mathrm{aTHF}, \mu \mathrm{mol} / 24 \mathrm{~h}$ & $4.16[1.94-6.31]$ & $3.74[21.8-6.06]$ & $5.29[3.34-8.35]$ & 0.92 & 0.07 & 0.02 \\
\hline
\end{tabular}

Data presented as median [IQR]; differences tested with a Mann-Whitney $U$ tests for nonparametric data; total active pool is defined as the sum of cortisol and cortisone excretion, $11 \beta-\mathrm{HSD} 1=(\mathrm{THF}+\mathrm{aTHF}) / \mathrm{THE}, 11 \beta-\mathrm{HSD} 2=$ cortisone $/$ cortisol, and $5 \alpha-$ reductase $=$ aTHF/THF. THE, tetrahydrocortisone; THF, tetrahydrocortisol; aTHF, allotetrahydrocortisol; $11 \beta$-HSD1, $11 \beta$-hydroxysteroid dehydrogenase type $1 ; 11 \beta$-HSD2, $11 \beta$-hydroxysteroid dehydrogenase type 2; ADPKD, autosomal dominant polycystic kidney disease; HC, healthy control; IgA, immunoglobulin A; IQR, interquartile range.

Vasopressin in Kidney Disease and in Patients Using a V2 Receptor Antagonist

Vasopressin, measured by its surrogate marker copeptin, was similar in ADPKD and IgA nephropathy patients, but significantly higher when comparing these 2 groups to healthy controls, with a median of 8.4 , IQR [4.5-19.8], and 11.5 [7.3-17.9] versus 4.7 [3.5-6.8] pmol/L ( $p=0.001$ and $p<0.001$, respectively). In response to $\mathrm{V} 2$ receptor antagonist treatment, plasma copeptin levels increased $>3$-fold in the ADPKD patients from a median value of 8.4 [4.5-19.8] to 28.4 [17.4-36.0] pmol/L and decreased again after ceasing V2 receptor antagonist treatment during the washout period $(9.6[4.1-18.5] \mathrm{pmol} / \mathrm{L}$, both $p<0.001)$. The effect of the use of a V2 receptor antagonist on water homeostasis was furthermore illustrated by the strong increase in 24-h urine volume: 2,490 [IQR: 1,930-3,090] $\mathrm{mL}$ on baseline, 5,770 [IQR: 4,350$7,520] \mathrm{mL}$ during treatment, and 2,270 [IQR: $1,900-$ $3,060] \mathrm{mL}$ after washout $(p<0.001)$.

\section{Glucocorticoids in ADPKD Patients, Healthy}

Controls, and IgA Nephropathy Patients

First, glucocorticoid excretion was compared between ADPKD patients and healthy controls. ADPKD patients had a significantly lower 24-h urinary excretion of cortisol $(0.23[0.19-0.30]$ vs. $0.34[0.22-0.51] \mu \mathrm{mol} / 24 \mathrm{~h}$, respectively, $p=0.007)$ and cortisone $(0.29[0.21-0.42]$ vs. 0.53 [0.36-0.67] $\mu \mathrm{mol} / 24 \mathrm{~h}$, respectively, $p<0.001$ ) (Table 2 ). Concurrently, $11 \beta-H S D 1$ activity was higher and $11 \beta$ HSD2 activity lower. The overall daily glucocorticoid production, as measured by the total $24 \mathrm{~h}$ urinary excretion of glucocorticoid compounds did not differ between the 2 groups $(p=0.32)$. In plasma, a significantly lower concentration of cortisone was found (41 [30-50] vs. 55 [45-63] $\mathrm{nmol} / \mathrm{L}$, respectively, $p<0.001$ ), but not of cortisol (see online suppl. Table 1; for all online suppl. material, see www.karger.com/doi/10.1159/000511000). Of interest, the cortisol precursor 11-deoxycortisol was found to be elevated in ADPKD (0.67 [0.35-0.79] vs. 0.35 [0.22-0.56] $\mathrm{nmol} / \mathrm{L}, p=0.03)$, while CYP11B1 enzyme activity was lower (547 [331-896] vs. $821[576-1,122], p=0.03)$. In the second control group, the IgA nephropathy patients, a similar glucocorticoid excretion pattern was found (Table 2). In Figure 1, a summary of these findings is presented. In the overall group, the urinary excretion of cortisol, cortisone, and calculated $11 \beta$-HSD 1 and $11 \beta$-HSD 2 activities correlated with the plasma values $(R=0.33, R=0.43$, $R=0.27$ and $R=-0.52$, respectively, all $p<0.05$ ). 
Fig. 1. Differences in glucocorticoid levels in patients with impaired kidney function impairment (both ADPKD and IgA nephropathy, $n=27$ in both groups) compared to healthy controls $(n=81)$. Arrows indicate increased or decreased levels, with bold print indicating a $p$ value $<0.05$ and normal print $<0.1$ compared with MannWhitney U tests. $11 \beta$-HSD1, $11 \beta$-hydroxysteroid dehydrogenase type $1 ; 11 \beta$-HSD2, $11 \beta$-hydroxysteroid dehydrogenase type 2 ; 11-DOC, 11-deoxycorticosterone; THE, tetrahydrocortisone; THF, tetrahydrocortisol; aTHF, allotetrahydrocortisol; ADP$\mathrm{KD}$, autosomal dominant polycystic kidney disease; Ig, immunoglobulin.

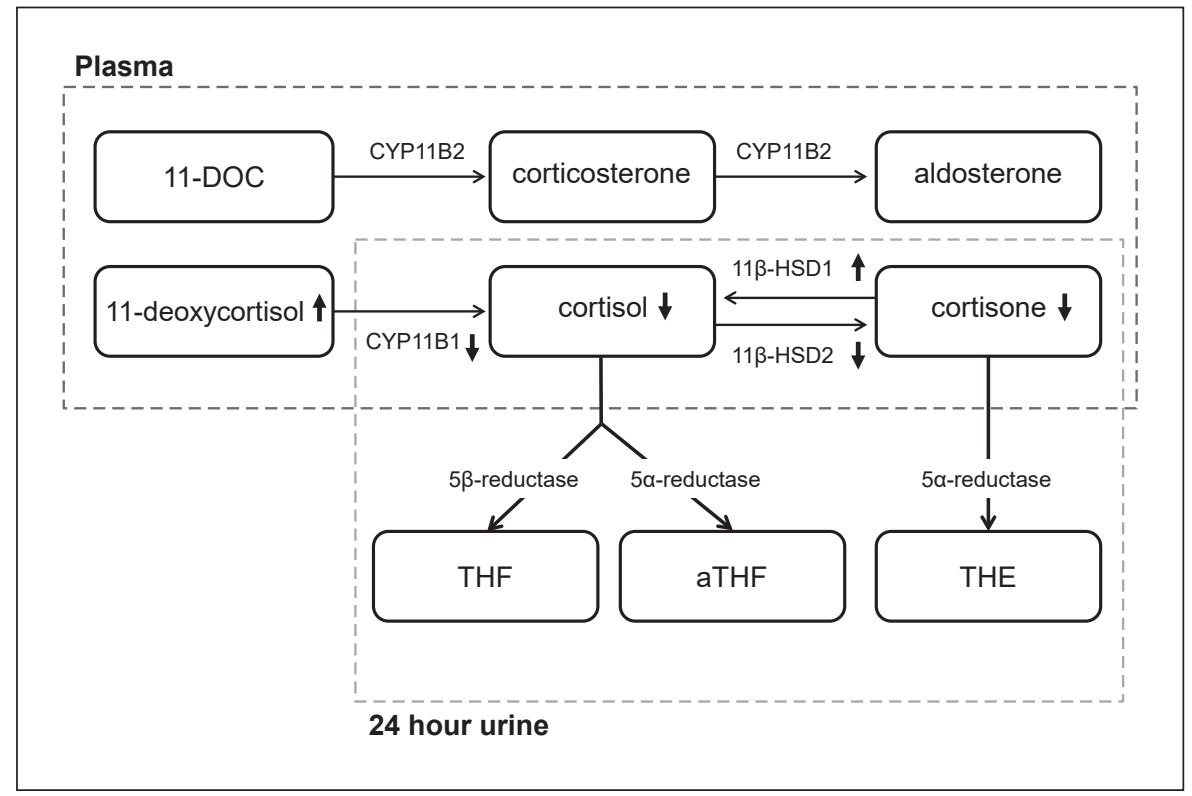

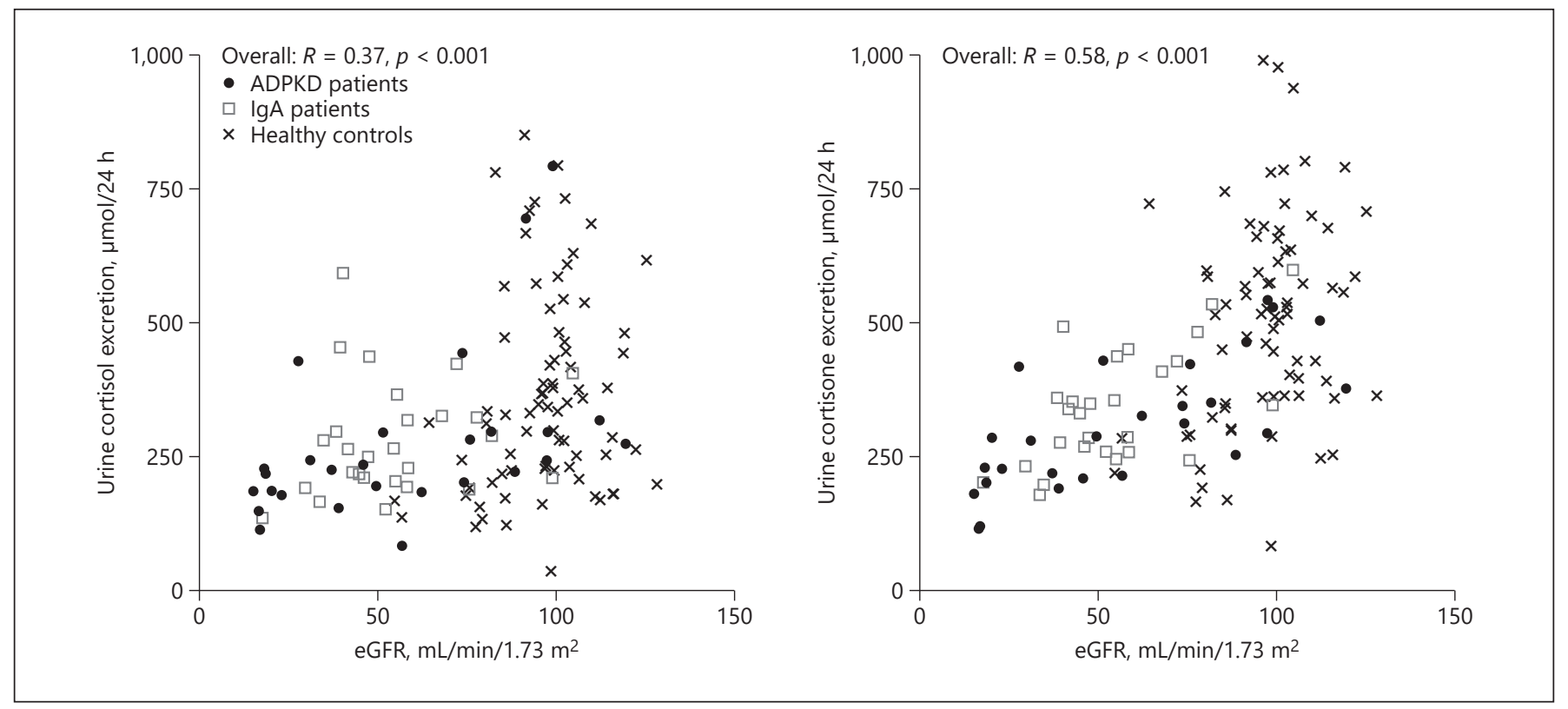

Fig. 2. Baseline kidney function versus urinary cortisol excretion (left panel) and urinary cortisone excretion (right panel). Correlation coefficients were assessed using Spearman's statistical tests for nonparametric data. ADPKD, autosomal dominant polycystic kidney disease; eGFR, estimated glomerular filtration rate; Ig, immunoglobulin.

There were differences in BMI and blood pressure between the 3 study groups. When we corrected our comparisons for BMI and blood pressure, similar results were obtained. Moreover, no significant interaction between BMI or blood pressure and study groups was found in the association with various components of the HPA axis.

Additionally, we investigated the correlations between eGFR and urinary excretion of glucocorticoids with Spearman's tests. The urinary excretion of cortisol, cortisone, 
Fig. 3. Changes in urinary and plasma glucocorticoid levels of ADPKD patients when using a vasopressin V2RA. Arrows indicate increased or decreased levels on treatment compared to baseline and washout, with bold print indicating a $p$ value $<0.05$ and normal print $<0.1$ using Friedman's ANOVA. $11 \beta$-HSD1, $11 \beta$-hydroxysteroid dehydrogenase type $1 ; 11 \beta$-HSD2, $11 \beta$-hydroxysteroid dehydrogenase type 2 ; 11-DOC, 11-deoxycorticosterone; THE, tetrahydrocortisone; THF, tetrahydrocortisol; aTHF, allotetrahydrocortisol; ADPKD, autosomal dominant polycystic kidney disease; RA, receptor antagonist; V2RA, vasopressin V2 receptor antagonist.

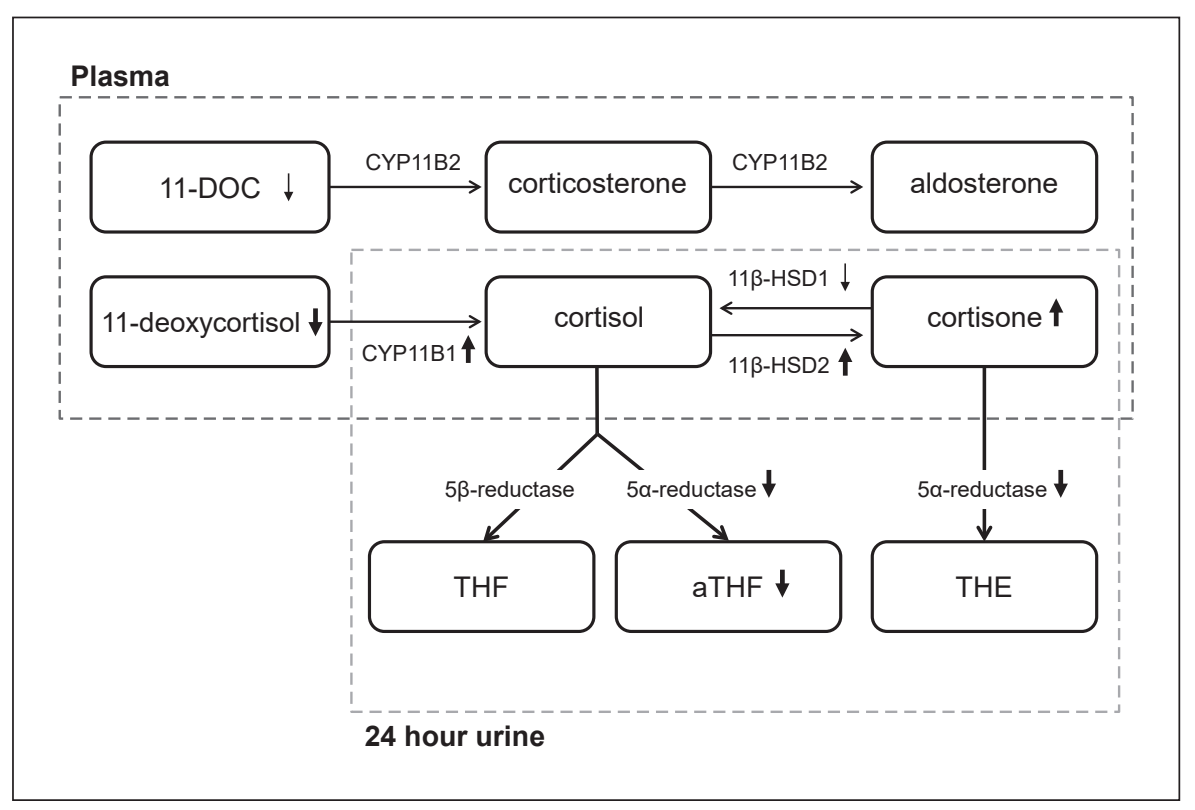

Table 3. Urinary excretion of glucocorticoids in ADPKD patients $(n=27)$ at baseline, after 3 weeks of treatment with the vasopressin V2RA tolvaptan and 3 weeks after stopping this treatment (washout)

\begin{tabular}{|c|c|c|c|c|}
\hline & Baseline & V2RA & Washout & $p$ value \\
\hline Total glucocorticoids, $\mu \mathrm{mol} / 24 \mathrm{~h}$ & $21.7[14.2-28.4]$ & $18.3[13.8-24.8]$ & $19.3[15.8-26.0]$ & 0.10 \\
\hline $\begin{array}{l}\text { Enzymes } \\
11 \beta \text {-HSD1 } \\
11 \beta \text {-HSD2 } \\
5 \alpha \text {-reductase }\end{array}$ & $\begin{array}{c}1.2[0.9-1.5] \\
1.2^{* *}[1.0-1.5] \\
0.56[0.38-1.0]\end{array}$ & $\begin{array}{c}1.0[0.6-1.5] \\
1.9[1.5-2.4] \\
0.43[0.25-0.95]\end{array}$ & $\begin{array}{c}1.1[0.9-1.6] \\
1.2^{* *}[1.0-1.3] \\
0.50^{*}[0.38-1.0]\end{array}$ & $\begin{array}{c}0.09 \\
<0.001 \\
0.04\end{array}$ \\
\hline
\end{tabular}

Data presented as median [IQR], differences tested with Friedman's ANOVA, for nonparametric data, with post hoc test with Bonferroni correction; ${ }^{*}<0.05 ;^{* *}<0.001$ compared to V2 receptor antagonist; total active pool is defined as the sum of cortisol and cortisone excretion, $11 \beta-H S D 1=(\mathrm{THF}+\mathrm{aTHF}) / \mathrm{THE}, 11 \beta-\mathrm{HSD} 2=$ cortisone/cortisol and $5 \alpha$-reductase $=$ aTHF/THF. THE, tetrahydrocortisone; THF, tetrahydrocortisol; aTHF, allotetrahydrocortisol; $11 \beta$-HSD1, $11 \beta$-hydroxysteroid dehydrogenase type 1; $11 \beta$-HSD2, $11 \beta$-hydroxysteroid dehydrogenase type 2; RA, receptor antagonist; ADPKD, autosomal dominant polycystic kidney disease; IQR, interquartile range; V2RA, vasopressin V2 receptor antagonist.

and total glucocorticoids was positively correlated with eGFR in the total group $(R=0.37, p<0.001 ; R=0.58, p<$ 0.001 ; and $R=0.19, p=0.03$, respectively, Fig. 2 and online suppl. Table 2). When these analyses were adjusted for age, sex, and copeptin levels, the associations remained (online suppl. Table 2). The enzyme activities of $11 \beta$-HSD 1 and $11 \beta$-HSD2 were also found to be correlated significantly $(R=-0.32$ and $R=0.32$, respectively, both $p<0.001)$. 
Glucocorticoids during Treatment with a V2 Receptor Antagonist

The effects of the V2 receptor antagonist on copeptin and 24-h urinary glucocorticoid excretion are shown in Table 3. During V2 receptor antagonist treatment copeptin increased, as did urinary excretion of cortisone (0.44 [0.35-0.61] vs. 0.29 [0.21-0.42] $\mu \mathrm{mol} / 24 \mathrm{~h}, p<$ $0.001)$ and the total active pool (0.71 [0.50-0.99] vs. 0.51 [0.42-0.73] $\mu \mathrm{mol} / 24 \mathrm{~h}, p<0.001) .11 \beta$-HSD2 activity increased (1.9 [1.5-2.4] vs. $1.2[1.0-1.5], p<0.001)$, whereas aTHF excretion decreased (3.5 [0.76-5.16] vs. 4.1 [1.94-6.31] $\mu \mathrm{mol} / 24 \mathrm{~h}, p<0.001)$. No difference in total urinary glucocorticoid excretion was observed $(p=0.10)$. These data are summarized in Figure 3.

Thereafter, V2 receptor antagonist induced changes in plasma glucocorticoid levels were investigated (online suppl. Table 3). No consistent changes were found during V2 receptor antagonist use when compared to baseline and washout.

\section{Discussion}

In this study, we explored whether an increase in plasma vasopressin concentration results in activation of the HPA axis. In concurrence with a strong increase in vasopressin during $\mathrm{V} 2$ receptor antagonist treatment, only cortisone, and not cortisol nor total urinary excretion of glucocorticoid products, was found to be increased. This makes it unlikely that increased vasopressin concentration in these patients results in clinically significant HPA axis activation. In addition, we found that cortisol and cortisone excretions were lower in proportion to the eGFR in our 3 study groups combined, suggesting that impaired kidney function has an effect on the HPA axis.

We conducted this study with the hypothesis that elevated vasopressin levels would result in a higher urinary glucocorticoid excretion because several lines of evidence suggest that vasopressin has a role in regulating HPA axis activity. First, it has been demonstrated in isolated cell lines and animal models that vasopressin regulates ACTH release from the anterior pituitary gland synergistically with CRH via the vasopressin V3 and the CRH-R1 receptors, respectively $[12,13]$. This occurs especially when activation of the axis is stress-induced [14]. Second, other experimental studies have shown that vasopressin leads to cortisol secretion from the adrenal cortex directly, by activation of vasopressin V1 and V3 receptors $[15,16]$. A comprehensive graphical overview of the above-de-

Glucocorticoid Metabolism in ADPKD scribed pathways can be found in online suppl. Figure 1 . That these experimental data can be translated to the human situation is supported by a study that showed that administration of a vasopressin V3 receptor antagonist reduced plasma ACTH, serum cortisol, urinary total glucocorticoids, and urinary cortisol excretion compared to placebo in healthy adults [33]. Furthermore, a second study showed correlations between stress-induced copeptin and cortisol concentrations when hypoglycemia was induced by insulin administration [34]. On the other hand, a clinical significant change in HPA-axis activation in states of vasopressin excess, as for example, SIAHD, has to the best of our knowledge not been described.

Our data challenge the clinical significance of the vasopressin effect on the HPA axis. In the context of a very pronounced elevation of vasopressin due to VR2A administration, we noticed only minor changes in the glucocorticoid axis. We found an increase in only a small part of the glucocorticoid axis, namely, in the size of the cortisone pool, the inactive counterpart of cortisol, in concurrence with an increase in $11 \beta$-HSD type 2 activation. However, cortisol level itself did not change. Moreover, overall glucocorticoid production showed a trend towards a lower value, contradicting our hypothesis. This observation is supported by a decrease in 11-deoxycortisol plasma levels, the direct cortisol precursor in the adrenal gland. Based on these data, we conclude that longterm V2 receptor antagonist administration is not likely to have detrimental off-target effects with regard to the HPA axis, thereby refuting the theoretical disadvantage of this drug in the treatment of ADPKD patients. Of note, the isolated change in cortisone excretion may not be influenced by vasopressin directly, but indirectly as a result of the increased urinary flow [35].

It is important to note that vasopressin levels are not only elevated when administering a V2 receptor antagonist, but that ADPKD patients had already higher levels at baseline when compared to healthy individuals. In $\mathrm{AD}$ PKD patients, the development and growth of renal cysts change the renal architecture, leading to a urine concentration defect [36-39]. To compensate for this concentration deficit, vasopressin levels are elevated in ADPKD patients [40]. Our data indicate that change in vasopressin levels is, however, not specific for this kidney disease because similar levels were found in IgA nephropathy patients that were matched to ADPKD patients for sex, age, and level of kidney function impairment. When comparing both patient groups to the healthy controls, again we did not find HPA axis activation. In contrast, kidney disease patients showed a marked downregulation of corti- 
sol and cortisone excretion in $24 \mathrm{~h}$ urine compared to age- and sex-matched healthy controls, although the overall glucocorticoid excretion remained similar. In our study population, a significant relationship between cortisol and cortisone and kidney function was seen. Prior studies have likewise reported a positive association between urinary cortisol excretion and kidney function in the general population [30] as well as in patients with kidney disease [41]. It has to be stated, however, that not all studies are uniform on this topic because another study did not find any difference between controls and patients with moderate to severe kidney function impairment in morning salivary cortisol concentration, as representation of plasma levels, and even higher levels of evening salivary cortisol in patients with more severe kidney impairment [42]. In our ADPKD and IgA nephropathy patients, a compensatory change towards more cortisol regeneration from cortisone was observed. The balance between cortisol and cortisone is maintained by 2 enzymes, $11 \beta$-HSD type 1 and type 2 . The first isoenzyme, $11 \beta$-HSD type 1 , functions primarily as reductase, which reduces cortisone to cortisol. The other isoenzyme, $11 \beta$-HSD type 2 , functions solely as dehydrogenase, thereby deactivating cortisol to cortisone. By doing so, $11 \beta$-HSD type 2 prevents binding of cortisol to the mineralocorticoid receptors. The latter conversion is of importance for salt regulation, for cortisol has an equal affinity for the mineralocorticoid receptor and thus equal effect as aldosterone, whereas cortisone has no binding potential $[25,43$, 44]. In line with prior research in adults and children, we found that $11 \beta$-HSD type 1 activity was negatively correlated with kidney function $[45,46]$. Also consistent with our data is literature that indicates that the functionality of $11 \beta$-HSD type 2 declines over the course of kidney disease $[47,48]$, although some data indicate that this phenomenon might only occur at severely impaired kidney function [49]. Since 11 $\beta$-HSD type 2 is an enzyme that operates principally in the kidney, progressive decline in kidney function may indeed be expected to affect its activity. Alternatively, rather than attributing these lower levels of urinary glucocorticoids and changed $11 \beta-H S D$ activities to a decreased kidney function, some suggests an effect of antihypertensive therapy [50], although literature on this subject is scarce and far from uniform, given that others do not find a link between use of these drugs and the glucocorticoid axis $[51,52]$. Importantly, when studying the effect of tolvaptan, patients were on a stable antihypertensive regimen.

We know of only one prior study that investigated the activity of the HPA axis in ADPKD patients. In this study,
Tufan et al. [53] subjected 22 ADPKD patients (eGFR: $89.7 \mathrm{~mL} / \mathrm{min} / 1.73 \mathrm{~m}^{2}$ ) and 27 healthy controls (eGFR: $105.6 \mathrm{~mL} / \mathrm{min} / 1.73 \mathrm{~m}^{2}$ ) to a $1 \mu \mathrm{g}$ short ACTH stimulation test. They found that ADPKD patients had higher basal plasma cortisol levels, in contrast to what we found, but that after ACTH stimulation plasma cortisol rose less in ADPKD patients compared to healthy controls. It should be noted that in their study, ADPKD patients had considerably better kidney function than in our study ( 90 vs. 57 $\mathrm{mL} / \mathrm{min} / 1.73 \mathrm{~m}^{2}$ ), possibly explaining the discrepancy in baseline cortisol data [53]. In addition, the ACTH test will only provide information on the presence or absence of adrenal insufficiency upon stimulation and is not a measure of day-to-day HPA axis activity.

With this study, we have investigated the significance of elevated vasopressin levels on the HPA axis within an actual clinical situation, which, to our knowledge, has not been done previously. We showed that during treatment with a V2 receptor antagonist, when vasopressin level increases, no disadvantageous effects on the HPA axis occur. Furthermore, we add information that CKD is associated with less glucocorticoid production, probably because of a decreased activity of $11 \beta$-HSD type 2 . We acknowledge that this study has limitations, most of which are inherent to the post hoc design. Most importantly, CRH and ACTH could not be measured in our stored samples, since these are small peptide hormones, which will be significantly influenced by frozen storage and thawing [54]. Another drawback is that we measured copeptin, as surrogate for vasopressin, instead of vasopressin. However, we previously showed that copeptin is more reliable to measure than vasopressin in stored samples [32]. Furthermore, it should be noted that our study addresses the effect of a V2 receptor antagonist on the HPA axis activity without addition of a stressor; therefore, we cannot definitively dismiss a vasopressin induced change of HPA axis regulation during stress conditions. Finally, we studied a relatively small patient population. Confirmation in a larger number of ADPKD patients may therefore be needed.

In conclusion, our data show that increased concentrations of vasopressin in patients on $\mathrm{V} 2$ receptor antagonist treatment do not result in overt activation of the HPA axis. In contrast, glucocorticoid production decreases in these patients in relation to the degree of their kidney function impairment.

\section{Acknowledgements}

We thank Frank Perton, Irene Wijbenga, and Henk Nijeboer for their skillful measurement of the copeptin and glucocorticoid levels. 


\section{Statement of Ethics}

All data was collected with approval of the ethical board of the University Medical Center Groningen and with adherence to the International Conference of Harmonization - Good Clinical Practice.

\section{Conflict of Interest Statement}

R.T.G. was a member of the Steering Committee of the TEMPO 3:4 and REPRISE trials that investigated the renoprotective effect of the $\mathrm{V} 2$ receptor antagonist tolvaptan in $\mathrm{ADPKD}$ and is a consultant for Otsuka Pharmaceutical Development \& Commercialization (Rockville, MD), the manufacturer of tolvaptan. All money was paid to his institution. The other authors have nothing to disclose.

\section{Funding Sources}

The authors did not receive any funding.

\section{Author Contributions}

Concept and design of this post hoc study were done by J.E.H., A.P.v.B., and R.T.G. Acquisition of the data was performed by W.E.B., R.T.G., and S.J.L.B. Development of the glucocorticoid measurement method was done by I.M., M.v.F., and I.K. Interpretation of the data and drafting of the manuscript were done by J.E.H., I.M., R.T.G., and A.P.v.B. All authors critically revised the manuscript for important intellectual content, agreed to publication, and can be held accountable for its content.

\section{References}

1 Torres VE, Harris PC, Pirson Y. Autosomal dominant polycystic kidney disease. Lancet. 2007;369(9569):1287-301.

2 Torres VE, Chapman AB, Devuyst O, Gansevoort RT, Grantham JJ, Higashihara E, et al. TEMPO 3:4 Trial Investigators: tolvaptan in patients with autosomal dominant polycystic kidney disease. N Engl J Med. 2012;367(25): 2407-18.

3 Boertien WE, Meijer E, de Jong PE, Ter Horst GJ, Renken RJ, van der Jagt EJ, et al. Shortterm effects of tolvaptan in individuals with autosomal dominant polycystic kidney disease at various levels of kidney function. Am J Kidney Dis. 2015;65(6):833-41.

4 Torres VE, Chapman AB, Devuyst O, Gansevoort RT, Perrone RD, Koch G, et al. REPRISE Trial Investigators: tolvaptan in laterstage autosomal dominant polycystic kidney disease. N Engl J Med. 2017;377(20):1930-42.

5 Gansevoort RT, van Gastel MDA, Chapman $A B$, Blais JD, Czerwiec FS, Higashihara E, et al. TEMPO 3:4 Investigators: plasma copeptin levels predict disease progression and tolvaptan efficacy in autosomal dominant polycystic kidney disease. Kidney Int. 2019;96(1):159_ 69.

6 Knepper MA, Kwon TH, Nielsen S. Molecular physiology of water balance. N Engl J Med. 2015;372(14):1349-58.

7 Miyazaki T, Fujiki H, Yamamura Y, Nakamura S, Mori T. Tolvaptan, an orally active vasopressin $\mathrm{V}(2)$-receptor antagonist: pharmacology and clinical trials. Cardiovasc Drug Rev. 2007;25(1):1-13.

8 Scott LV, Dinan TG. Vasopressin and the regulation of hypothalamic-pituitary-adrenal axis function: implications for the pathophysiology of depression. Life Sci. 1998;62(22):1985-98.

9 Koshimizu TA, Nakamura K, Egashira N, Hiroyama $M$, Nonoguchi $H$, Tanoue A. Vasopressin V1a and V1b receptors: from molecules to physiological systems. Physiol Rev. 2012;92(4):1813-64.
10 Rotondo F, Butz H, Syro LV, Yousef GM, Di Ieva A, Restrepo LM, et al. Arginine vasopressin (AVP): a review of its historical perspectives, current research and multifunctional role in the hypothalamo-hypophysial system. Pituitary. 2016;19(4):345-55.

11 Nakamura K, Velho G, Bouby N. Vasopressin and metabolic disorders: translation from experimental models to clinical use. J Intern Med. 2017;282(4):298-309.

12 Gillies GE, Linton EA, Lowry PJ. Corticotropin releasing activity of the new CRF is potentiated several times by vasopressin. Nature. 1982;299(5881):355-7.

13 Rivier C, Vale W. Modulation of stress-induced ACTH release by corticotropin-releasing factor, catecholamines and vasopressin. Nature. 1983;305(5932):325-7.

14 Zelena D, Domokos A, Jain SK, Jankord R, Filaretova L. The stimuli-specific role of vasopressin in the hypothalamus-pituitary-adrenal axis response to stress. J Endocrinol. 2009; 202(2):263-78

15 Perraudin V, Delarue C, Lefebvre H, Contesse V, Kuhn JM, Vaudry H. Vasopressin stimulates cortisol secretion from human adrenocortical tissue through activation of V1 receptors. J Clin Endocrinol Metab. 1993;76(6): 1522-8.

16 Guillon G, Trueba M, Joubert D, Grazzini E, Chouinard L, Côté M, et al. Vasopressin stimulates steroid secretion in human adrenal glands: comparison with angiotensin-II effect. Endocrinology. 1995;136(3):1285-95.

17 Di Dalmazi G, Vicennati V, Garelli S, Casadio E, Rinaldi E, Giampalma E, et al. Cardiovascular events and mortality in patients with adrenal incidentalomas that are either non-secreting or associated with intermediate phenotype or subclinical Cushing's syndrome: a 15-year retrospective study. Lancet Diabetes Endocrinol. 2014;2(5):396-405.

18 Park J, De Luca A, Dutton H, Malcolm JC, Doyle MA. Cardiovascular outcomes in au- tonomous cortisol secretion and nonfunctioning adrenal adenoma: a systematic review. J Endocr Soc. 2019;3(5):996-1008.

19 Turkmen K, Oflaz H, Uslu B, Cimen AO, Elitok A, Kasikcioglu E, et al. Coronary flow velocity reserve and carotid intima media thickness in patients with autosomal dominant polycystic kidney disease: from impaired tubules to impaired carotid and coronary arteries. Clin J Am Soc Nephrol. 2008;3(4):986-91.

20 Ecder T, Schrier RW. Cardiovascular abnormalities in autosomal-dominant polycystic kidney disease. Nat Rev Nephrol. 2009;5(4): 221-8.

21 Ravine D, Gibson RN, Walker RG, Sheffield LJ, Kincaid-Smith P, Danks DM. Evaluation of ultrasonographic diagnostic criteria for autosomal dominant polycystic kidney disease 1. Lancet. 1994;343(8901):824-7.

22 de Jong WHA, Buitenwerf E, Pranger AT, Riphagen IJ, Wolffenbuttel BHR, Kerstens $\mathrm{MN}$, et al. Determination of reference intervals for urinary steroid profiling using a newly validated GC-MS/MS method. Clin Chem Lab Med. 2017;56(1):103-12.

23 Tent H, Rook M, Stevens LA, van Son WJ, van Pelt LJ, Hofker HS, et al. Renal function equations before and after living kidney donation: a within-individual comparison of performance at different levels of renal function. Clin J Am Soc Nephrol. 2010;5(11):1960-8.

24 Werumeus Buning J, van Faassen M, Brummelman P, Dullaart RP, van den Berg G, van der Klauw MM, et al. Effects of hydrocortisone on the regulation of blood pressure: results from an RCT. J Clin Endocrinol Metab. 2016;101(10):3691-9.

25 Courtney R, Stewart PM, Toh M, Ndongo MN, Calle RA, Hirshberg B. Modulation of 11beta-hydroxysteroid dehydrogenase (11betaHSD) activity biomarkers and pharmacokinetics of PF-00915275, a selective 11betaHSD1 inhibitor. J Clin Endocrinol Metab. 2008;93(2):550-6. 
26 Tomlinson JW, Finney J, Hughes BA, Hughes SV, Stewart PM. Reduced glucocorticoid production rate, decreased 5alpha-reductase activity, and adipose tissue insulin sensitization after weight loss. Diabetes. 2008;57(6):153643.

27 Cuzzola A, Mazzini F, Petri A. A comprehensive study for the validation of a LC-MS/MS method for the determination of free and total forms of urinary cortisol and its metabolites. J Pharm Biomed Anal. 2014;94:203-9.

28 Bureik M, Lisurek M, Bernhardt R. The human steroid hydroxylases CYP1B1 and CYP11B2. Biol Chem. 2002;383(10):1537-51.

29 Garde AH, Hansen AM. Long-term stability of salivary cortisol. Scand J Clin Lab Invest. 2005;65(5):433-6.

30 Rosmalen JG, Kema IP, Wüst S, van der Ley C, Visser ST, Snieder H, et al. $24 \mathrm{H}$ urinary free cortisol in large-scale epidemiological studies: short-term and long-term stability and sources of variability. Psychoneuroendocrinology. 2014;47:10-6.

31 Kleeberger C, Shore D, Gunter E, Sandler DP, Weinberg CR. The effects of long-term storage on commonly measured serum analyte levels. Epidemiology. 2018;29(3):448-52.

32 Heida JE, Boesten LS, Ettema EM, Muller Kobold AC, Franssen CF, Gansevoort RT, et al. Comparison of ex vivo stability of copeptin and vasopressin. Clin Chem Lab Med. 2017; 55(7):984-92.

33 Katz DA, Locke C, Liu W, Zhang J, Achari R, Wesnes KA, et al. Single-dose interaction study of the arginine vasopressin type $1 \mathrm{~B}$ receptor antagonist ABT-436 and alcohol in moderate alcohol drinkers. Alcohol Clin Exp Res. 2016;40(4):838-45.

34 Kacheva S, Kolk K, Morgenthaler NG, Brabant G, Karges W. Gender-specific co-activation of arginine vasopressin and the hypothalamic-pituitary-adrenal axis during stress. Clin Endocrinol. 2015;82(4):570-6.

35 Mussig K, Remer T, Fritsche A, Haring HU, Maser-Gluth C. Urinary free cortisone, but not cortisol, is associated with urine volume in severe obesity. Steroids. 2009;74(9):742-5.

36 Ho TA, Godefroid N, Gruzon D, Haymann JP, Maréchal C, Wang X, et al. Autosomal dominant polycystic kidney disease is associated with central and nephrogenic defects in osmoregulation. Kidney Int. 2012;82(10):1121-9.
37 Zittema D, Boertien WE, van Beek AP, Dullaart RP, Franssen CF, de Jong PE, et al. Vasopressin, copeptin, and renal concentrating capacity in patients with autosomal dominant polycystic kidney disease without renal impairment. Clin J Am Soc Nephrol. 2012;7(6):906-13.

38 Chebib FT, Sussman CR, Wang X, Harris PC, Torres VE. Vasopressin and disruption of calcium signalling in polycystic kidney disease. Nat Rev Nephrol. 2015;11(8):451-64.

39 Zittema D, Casteleijn NF, Bakker SJ, Boesten LS, Duit AA, Franssen CF, et al. Urine concentrating capacity, vasopressin and copeptin in ADPKD and IgA nephropathy patients with renal impairment. PLoS One. 2017; 12(1): 0169263.

40 Meijer E, Bakker SJ, van der Jagt EJ, Navis G, de Jong PE, Struck J, et al. Copeptin, a surrogate marker of vasopressin, is associated with disease severity in autosomal dominant polycystic kidney disease. Clin J Am Soc Nephrol. 2011;6(2):361-8.

41 Chan KC, Lit LC, Law EL, Tai MH, Yung CU, Chan $\mathrm{MH}$, et al. Diminished urinary free cortisol excretion in patients with moderate and severe renal impairment. Clin Chem. 2004; 50(4):757-9.

42 Cardoso EM, Arregger AL, Budd D, Zucchini AE, Contreras LN. Dynamics of salivary cortisol in chronic kidney disease patients at stages 1 through 4. Clin Endocrinol. 2016;85(2): 313-9.

43 van Uum SH, Hermus AR, Smits P, Thien T, Lenders JW. The role of 11 beta-hydroxysteroid dehydrogenase in the pathogenesis of hypertension. Cardiovasc Res. 1998;38(1):16-24.

44 Hunter RW, Bailey MA. Glucocorticoids and 11beta-hydroxysteroid dehydrogenases: mechanisms for hypertension. Curr Opin Pharmacol. 2015;21:105-14.

45 Mongia A, Vecker R, George M, Pandey A, Tawadrous H, Schoeneman M, et al. Role of 11betaHSD type 2 enzyme activity in essential hypertension and children with chronic kidney disease (CKD). J Clin Endocrinol Metab. 2012;97(10):3622-9.
46 Sagmeister MS, Taylor AE, Fenton A, Wall NA, Chanouzas D, Nightingale PG, et al. Glucocorticoid activation by 11 beta-hydroxysteroid dehydrogenase enzymes in relation to inflammation and glycaemic control in chronic kidney disease: a cross-sectional study. Clin Endocrinol. 2019;90(1):241-9.

47 Quinkler M, Zehnder D, Lepenies J, Petrelli MD, Moore JS, Hughes SV, et al. Expression of renal 11beta-hydroxysteroid dehydrogenase type 2 is decreased in patients with impaired renal function. Eur J Endocrinol. 2005; 153(2):291-9.

48 Gant CM, Minovic I, Binnenmars H, de Vries L, Kema I, van Beek A, et al. Lower renal function is associated with derangement of $11-\beta$ hydroxysteroid dehydrogenase in type 2 diabetes. J Endocr Soc. 2018;2(7):609-20.

49 Hammer F, Edwards NC, Hughes BA, Steeds RP, Ferro CJ, Townend JN, et al. The effect of spironolactone upon corticosteroid hormone metabolism in patients with early stage chronic kidney disease. Clin Endocrinol. 2010;73(5):566-72.

50 Dullaart RP, Ubels FL, Hoogenberg K, Smit AJ, Pratt JJ, Muntinga JH, et al. Alterations in cortisol metabolism in insulin-dependent diabetes mellitus: relationship with metabolic control and estimated blood volume and effect of angiotensin-converting enzyme inhibition. J Clin Endocrinol Metab. 1995;80(10): $3002-8$

51 Sasaki M, Fujimura A, Harada K, Sunaga K, Ebihara A. Effect of losartan, an angiotensin II receptor antagonist, on response of cortisol and aldosterone to adrenocorticotrophic hormone. J Clin Pharmacol. 1995;35(8):776-9.

52 Ghazi L, Dudenbostel T, Hachem ME, Siddiqui $\mathrm{M}$, Lin $\mathrm{CP}$, Oparil S, et al. 11-beta dehydrogenase type 2 activity is not reduced in treatment resistant hypertension. Am J Hypertens. 2017;30(5):518-23.

53 Tufan F, Uslu B, Cekrezi B, Uysal M, Alpay N, Turkmen K, et al. Assessment of adrenal functions in patients with autosomal dominant polycystic kidney disease. Exp Clin Endocrinol Diabetes. 2010;118(10):741-6.

54 Hillebrand JJ, Heijboer AC, Endert E. Effects of repeated freeze-thaw cycles on endocrine parameters in plasma and serum. Ann Clin Biochem. 2017;54(2):289-92. 